that there was more evidence of obstructive respiratory disease in his sample of workers than among the workers exposed to similar products examined by ourselves. 1 On the other hand, the F.E.V./V.C. ratio is not age standardized and differences in age structure of the two populations might to some extent account for the difference. Also, a higher proportion of the workers in his survey were sensitized to the $B$. subtilis derivatives than in our own series.

Levels of enzyme concentration in air are not given, but exposure to higher levels for longer periods might account for the difference.-I am, etc.

MURIEL Newhouse.

\section{London School of Hygiene and}

ropical Medicine

\section{REFERENCB}

1 Newhouse, M. L., Tagg, B., Pocock, S. J.,

\section{Hypotension Caused by L-Dopa}

SIR,-I have read with interest the report of Dr. D. B. Calne and his colleagues (21 February, p. 474), regarding hypotension caused by L-dopa in patients with Parkinson's disease, and the subsequent comment of Professor J. H. Burn (7 March, p. 629) on the mechanism of this effect. If patients on chronic L-dopa therapy are in fact secreting dopamine from their sympathetic nerve terminals, then a beta-adrenergic blocking agent such as propranolo should antagonize this effect, since dopamine appears to have predominantly betaadrenergic properties. ${ }^{1}$ This line of reasoning led us to attempt the administration of propranolol to a small number of patient on L-dopa treatment who had developed symptomatic hypotension. We observed in several an abrupt cessation of symptom and a partial correction of the hypotension. One paiient had a particularly striking response.

A 46-year-old woman with Parkinson's disease of six years' duration presented as a severe primarily bradykinetic parkinsonian with minimal tremor and only mild rigidity. She required assistance to arise from a sitting position, stood with markedly stooped posture, and could barely walk with small shuffling steps festinating very severely. Blood pressure was $110 / 70$ sitting or standing. The pulse was $80 /$ minute and regular.

Treatment with laevodopa was begun in August 1968 at a daily dose of $1 \mathrm{~g}$. When the daily dose was increased to $2 \mathrm{~g}$, the patient complained of "dizziness" when standing. Blood pressure fell to $95 / 70$ on one occasion with no increase in pulse rate. Her symptoms were controlled with the use of elastic bandages on the legs and the daily dose of L-dopa was gradually increased to 3,4 , and finally $5 \mathrm{~g}$. A this dose level there was appreciable improvement. Rigidity was abolished to be replaced by a general hypotonia. However, she was still occasionally dizzy and blood pressure fell to $70 / 50$ on standing-despite the use of elastic bandages and an abdominal binder. Continuin symptoms of postural hypotension compelled further reduction of the dose to $3.5 \mathrm{~g}$. per day, on which she continued for a year without any change in hypotensive symptoms.

Various amphetamines including dextroamphetamine, ephedrine, propylhexedrine, and hydroxyamphetamine were tried with negative results. Propranolol was then begun in November 1969 at a dose of $10 \mathrm{mg}$. t.i.d. There was a prompt and striking subjective response. The patient had no further syncopal episodes and no longer experienced light-headedness on standing up. The daily dosage of laevodopa was increased to $4.5 \mathrm{~g}$. without a recrudescence of these symptoms.

The patient was then readmitted and after a period of observation, propranolol was discontinued. Blood pressure readings were consistently lower without the propranolol. Faintness and light-headedness and several brief syncopal episodes occurred despite the use of elastic bandages in the lower extremities. These symptoms were so severe that the patient was unable to assume the upright position. After a three day hiatus, propranolol was resumed. Blood pressure readings returned to the levels previously observed and symptoms of orthostatic hypotension became milder and less frequent. No further syncopal episodes occurred. Propranolol was withdrawn a second time for several days with similar results. Advantage was taken of the apparent protection afforded by propranolol to increase the dosage of laevodopa by gradual increments ultimately to a total daily dose of $8 \mathrm{~g}$. per day. The dose of propranolol was also gradually increased to $30 \mathrm{mg}$. given four times daily. On this regimen the patient still had some occasional low blood pressure readings, circa $90 / 60$ or $80 / 50$, but rarely experienced faintness or light-headedness and had no syncopal reactions. The pulse remained slow at $50-60 / \mathrm{min}$. The increased dose of L-dopa yielded some additional significant improvements. The patient has maintained these improvements for the past six months.

While further experience is necessary to assess the clinical value of propranolol in treating L-dopa-induced hypotension, our preliminary experience indicating that it can at least partially antagonize this effect of $L$ dopa gives some support to the views advanced by Dr. Calne and colleagues, and by Professor Burn.-I am, etc.

Roger C. Duvorsin.

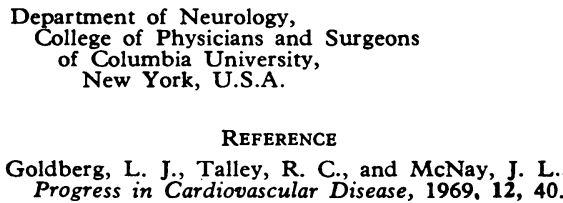

\section{Pseudo-obstruction of the Large Bowel}

SIR,-The article by Mr. P. K. Caves and Dr. H. A. Crockard (6 June, p. 583) on pseudo-obstruction of the large bowel was very interesting. I was surprised, however that in no case was the simple procedure of a diagnostic enema applied, where there was no contraindication such as evidence of peritonitis. It is possible on occasion to avoid laparotomy in these circumstances by its use.-I am, etc.,

\section{County Hospital,

$$
\text { Hereford. }
$$

Hugh Davies.

\section{Smallpox Vaccination}

SIR,-I am delighted by your leading article (9 May, p. 311) supporting our position on curtailing routine smallpox vaccination. This same conclusion was reached by Dick, ${ }^{1}$ when reviewing data from Great Britain.
I am concerned that you support the thesis that a safer vaccine may solve most of our problems in smallpox control. The death rate from smallpox vaccination is in the order of one per million primary vaccinations, and the incidence of severe complications such as post-vaccinal encephalitis is only about five per million primary vaccinations. It is evident that only a massive trial involving several millions of vaccinees could convincingly demonstrate greater safety of a new strain. If greater safety of a new strain will be difficult to prove, acceptable efficacy will be equally so. At present there is so little smallpox in the world, even in India and Pakistan, that it would be exceedingly difficult to carry out a field trial of a new vaccine to prove its efficacy.

While I am delighted to see the academic interest in attenuated strains, I feel we should not expect them to be introduced for routine use. The only way to reduce the current toll of vaccination complications in non-endemic nations, then, is reduction of the number of vaccinations performed.-I am, etc.,

\section{J. Michael Lane,}

$$
\begin{gathered}
\text { School of Public Health, } \\
\text { University of California, } \\
\text { Berkeley, California, U.S.A }
\end{gathered}
$$

\section{REFERENCE}

1 Dick, G., Progress in Medical Virology, 1966, 8,

\section{Epidemic Malaise}

SIR,-Dr. D. C. Poskanzer (16 May, p 420) rightly draws attention to the need to apply the principles of epidemiology to the study of epidemics of benign myalgic encephalomyelitis (epidemic neuromyesthenia).

The basic features of the condition as seen in a general practice in North London between 1964 and 1966 by Dr. Betty D. Scott (17 January, p. 170) were identical to those described by Wallis ${ }^{12}$ in a general practice at Dalston, Cumberland, between January and August 1955. Extensive virological studies carried out at the Public Health Laboratories in Carlisle and at Colindale were negative. Apart from the frequent finding of cortical depression, objective neurological changes were found in $20 \%$ of cases and indicated a widespread involvement. Upper motor neurone lesions with extensor plantar responses were recorded in two cases; ataxia, nystagmus, positive Romberg test, and a patchy motor weakness with brisk tendon reflexes and hypotonic muscles were found in others, and muscle atrophy with ulnar nerve lesions occurred in eight patients.

The latter complication was probably responsible for my first contact with the epidemic, as the number of ulnar nerve lesions referred to my electrodiagnostic clinic in the neighbouring county of Durham early in July 1955 suddenly increased five-fold (none was from Dalston). Ulnar nerve involvement had been reported in previous epidemics in Iceland ${ }^{3}$ (1948) and New York State $^{4}$ (1950). Later in 1955 and in 1956 a few cases with more generalized motor weakness were seen in Co. Durham. On electromyography the characteristic grouping illustrated in Drs. C. P. McEvedy and A. W. Beard's article (3 January, p. 7) was not 